\title{
Understanding and measuring cooking skills and knowledge as factors influencing convenience food purchases and consumption
}

\author{
Sabrina Ternier
}

\begin{abstract}
This manuscript was prepared under the supervision of Professor Andreas Boecker, Department of Food, Agricultural \& Resource Economics, Ontario Agricultural College.
\end{abstract}

\begin{abstract}
As the convenience food industry becomes more prominent in society, it is essential to understand the influence of cooking competence on home food production. Cooking competence allows a consumer to be self reliant and have a healthy diet, creates a less stressful home food production process and influences the consumer's orientation attitude towards pre-prepared convenience foods. Through a literature review, it was found that mothers and cooking classes are the most important sources to acquire cooking skills, while factors such as gender, age, income, social/educational class, attitude and social environment determine how one acquires their cooking competence. A non-traditional definition of cooking competence was analyzed which strays from the traditional 'task centered' approach and instead encompasses a comprehensive set of skills used in domestic cooking. A cooking competence questionnaire was created to include this new definition.
\end{abstract}

$\mathrm{T}$ he high-speed and time-constrained lifestyle of many Western countries has led to the rise of the food convenience industry and its significant impact on society's food consumption behaviours. Convenience foods can be defined as a food product which is beneficial to the customer during any of the meal preparation and consumption stages: ${ }^{2}$ planning, purchasing, storing, preparation, eating and disposal/tidy-up. ${ }^{18}$ This means a product which can be easily obtained, prepared, stored, served, or eaten, thus proving to be convenient by saving time, physical energy and/or mental energy. ${ }^{2}$ With the high availability of frozen prepared meals, grocery prepared meals, fast take-out and sit-down restaurants, many people are now eating less home prepared meals and more convenience foods. In 1992, 36\% of the American population ate three or more pre-prepared convenience foods weekly; this increased to $41 \%$ within eight years. ${ }^{11}$ Additionally, while the percentage of American home prepared meal expenditures have decreased from roughly $70 \%$ of total food expenditure in 1965 to $53 \%$ in 2000 , the expenditures of food consumed away from home have increased from $30 \%$ to $47 \%$ within the same timeframe. ${ }^{7}$

Many factors have been researched as to what determines a consumer's convenience orientation which ultimately impacts the consumer's decision of convenience food purchasing and full meal preparation activities. Widely researched factors have been respondents' time availability, income, beliefs/attitudes, such as convenience orientation, and product characteristics, such as preparation effort or price. ${ }^{18}$ However, the interdependencies of cooking competence (combination of both knowledge and skills) and home meal preparation and convenience food purchasing are poorly understood. Short proposes that the convenience food industry has led to the 'deskilling' of households with regards to home cooking, and found through a literature review that there are others who believe otherwise stating that these set of skills are evolving and being transformed. ${ }^{15}$ According to Braverman's theory of deskilling in the industrial workplace, a worker is only assigned to complete one part of a larger project, and thus becomes 'divorced from the complete process. ${ }^{15}$ The division of a task into multiple simplified segments 'deskills' the worker and turns it into a routine. This 'deskilling' is believed to also take place in cooking due to the high availability of pre-prepared meals and is perpetuated by parents who use pre-prepared meals as they will give their children fewer opportunities to learn cooking skills. $^{15}$

The objective of this literature review is thus to develop a deeper understanding of cooking competence which will contribute to developing a survey on the role of convenience in food choices. This will be achieved by examining their relationship to nutritional knowledge and convenience food purchasing, determining how cooking skills are acquired and what factors affect them, and by exploring a method to measure cooking skills empirically. These tasks form the remaining sections of this review which will be presented in the above sequence, after a general discussion of the importance of cooking competence for food preparation at home is presented in the next section. 


\section{THE IMPORTANCE OF COOKING COMPETENCE}

Cooking competence is important as it affects self-reliability, nutritional knowledge, dietary behaviour and quality, as well as personal health. It also affects the home meal preparation and consumption process and the way in which a household is able to handle stressful situations.

Firstly, cooking competence equips the consumer with abilities to prepare meals for him or herself. ${ }^{5}$ Soliah and Walter showed how their subjects would prepare a meal if they only knew how to. ${ }^{17}$ At first, only $23 \%$ of the college women prepared quiche in the study; but once they were taught its food preparation knowledge, the number rose to $85 \%$. Without cooking competence, the consumer will be more inclined to consuming meals that were pre-prepared at groceries or are frozen, as well as from take-out or restaurants. ${ }^{11}$ This can also be seen in the study of college women which showed that those who ate out more frequently also had fewer cooking skills to prepare common meals such as potato salads and enchiladas. ${ }^{17}$

Secondly, the possession of cooking knowledge and skills to improve nutritional knowledge and one's ability to prepare meals, will also affect dietary quality. Cooking competence would enable a consumer to prepare and incorporate the vital foods for a healthy diet and would broaden their food selection. This could lead to higher consumption of healthier foods such as fruits, vegetables and grains, ${ }^{11}$ as seen in the study by Larson et al., which found that those who prepared home meals often were more likely to attain dietary standards set by Healthy People 2010.; 10 More specifically, that study found that respondents with high meal preparation involvement scores consumed the recommended five servings a day of fruit and vegetable significantly more often (31\%) than those who used more convenience food products (3\%). Additionally, home prepared meals have a higher dietary quality than restaurant food. According to Soliah and Walter, they have higher levels of nutrients, fibre and essential vitamins and minerals, as well as lowered cholesterol and saturated/trans-fatty acid levels. Overall, the few studies on the effects of home food preparation on dietary quality have concluded that there is a strong positive relationship between the two. ${ }^{10,17}$

Thirdly, the absence of cooking competence will result in reliance on and trust in the convenience food industry, a lowered nutritional health and may decrease one's ability to multi-task within a demanding family lifestyle. If one is unable to cook for themselves due to a lack of cooking knowledge and skills, the consumer is reliant on pre-prepared meals and restaurants, ${ }^{11,17}$ or others such as a spouse or family member to cook for them. ${ }^{5,9}$ The consumer is also putting trust in the convenience food product that its nutritional information and statements are accurate. ${ }^{5}$ I argue that this trust is all-encompassing and reduces awareness of all the measures necessary for proper food preparation to meet food safety and nutritional requirements. This applies to food hygiene measures, measures to avoid exposure to allergenic ingredients, such as peanuts, and the impact of food perseveration and processing on macro and micro nutrients. As mentioned previously, home prepared meals have higher nutritional quality and fewer calories than those of convenience and restaurant foods; $;{ }^{11}{ }^{17}$ thus being unable to cook for oneself could result in lowered health due to less nutrient intake. This can be seen in the literature review by Larson et al. which states that the inadequate dietary attainment by young adults ranging from 18 to 24 years old is related to their high convenience food consumption as these foods are less healthy.

Lastly, if a non-traditional approach is taken to defining cooking competence as more than just technical skills, one can see how they can be beneficial to the stages of the home food production chain such as planning, storing/handling, preparation, eating, and disposal. For example, planning and organizing skills help with the first stage of the home food production chain, mechanical and technical skills are used for the preparation stage, and fundamental knowledge of food hygiene is useful throughout the storing/handling, preparation and disposal stages. Therefore, lack of cooking competence may impair one's ability to multi-task in a demanding family situation. When there are time constraints in a fast paced or stressful lifestyle, being able to do multiple tasks simultaneously is an advantage. If the meal provider is unable to cook whilst doing laundry and taking care of the children, then he or she may be less likely to prepare a home meal. Also, if the meal provider is unable to plan and organize a meal, or unable to create a meal that will satisfy those who are eating it, he or she may find it easier to buy a convenience food product that will save time and energy, and be satisfying to everyone. Defining cooking competence and its complexity is explored in depth later in the paper.

\section{The Relationship to NuTRITION KNOWLEDGE}

Nutrition knowledge is not sufficient by itself to implement dietary guidelines and improve dietary standards, but instead only provides the information of how to form a healthy diet. ${ }^{8}$,

${ }^{17}$ Culinary classes or home economic classes have been removed from many educational systems, such as those of Britain's in 1988, and instead have been replaced with more theoretical classes such as 'Science, Design and Technology' or 'Health Education,' which only cover nutrition knowledge. ${ }^{8}$ This removal of cooking classes in school has led many to believe that the nutrition education is insufficient and takes away a vital opportunity for children to learn techniques needed to prepare healthy meals. Frobisher et al. have concluded that the dietary behaviour of the adolescents in Merseyside, England was not reflective of their nutrition knowledge. ${ }^{8}$

Research has shown that when dealing with children, active cooking experiences combined with nutrition knowledge instead of solely theoretical nutrition knowledge 
is more effective in changing dietary behaviour. ${ }^{5}, 12$ Additionally, increased cooking competence can result in better nutrition knowledge. ${ }^{11}$ A nutrition intervention called the 'Cookshop Programme' conducted a study which consisted of cook shop, food, and environmental lessons. ${ }^{12}$ Elementary school children were given different combinations of lessons, for example, cook shop lessons only, cook shop and food lessons, etc. The results revealed that active experiences during cooking classes increased knowledge and preference of vegetables and fruits in both young and older children, increased behavioural intentions to consume healthy foods in younger children, and increased cooking self-efficacy in older children. ${ }^{12}$ This study concluded that cognitive learning of nutrition is not the best method of changing dietary behaviour and that active learning experiences through cooking and food preparation are needed. The study also showed the importance of home economics or culinary classes within the educational system as a means of providing the nutritional knowledge and cooking competence needed for everyday life.

To emphasize how cooking experiences assist nutrition knowledge in achieving healthy diets, it can be useful to view nutrition knowledge as the 'what to eat' and the cooking knowledge as the 'how to make it." ${ }^{17}$ This clearly shows the relationship the two factors have towards dietary behaviour. In a study of young adults, $23 \%$ of males and $18 \%$ of females reported that lack of cooking competence created a barrier to food preparation. ${ }^{10}$ If one knows what foods are healthy to eat, or what preparation techniques are healthier (fried egg versus poached egg) but is unable to make that healthy meal, his or her knowledge cannot be fully realized.

\section{THE RELATIONSHIP TO FOOD PURCHASING}

The relationship between cooking competence and food purchasing and consumption has several aspects. As mentioned previously, increased cooking competence allows for a broader variety of items to be prepared, increases intentions to buy more fresh produce as well as increases their consumption. ${ }^{11}$ Therefore it can be assumed that the more cooking competence one has, the wider the coverage of the five basic food categories. Additionally, as stated earlier, if the consumer lacks cooking competence, he or she is more inclined to buy pre-prepared meals or eat out. ${ }^{11,17}$ Cooking knowledge and skills also provide the consumer with knowledge of how a pre-prepared convenience meal was prepared, ${ }^{5}$ and thus may prove helpful in determining the healthier choice amongst the convenience meals. Furthermore, the possession of cooking skills allows the consumer to be able to make several types of meals from one food product, thus decreasing food costs. ${ }^{16}$ A study of older Swedish women revealed that their acquired cooking skills over the years allowed them to prepare different dishes from one meat product. '...I buy marrowbone or rib, then I can have both beef stew and boiled beef with horseradish sauce' shows the cooking competence of a Swedish woman. ${ }^{16}$ She is able to plan, organize and conceptualize which food product can create the most meals. This skill allows for lowered food costs as the consumer is able to get her money's worth. Lastly, it has been believed by many that cooking competence excludes the use of convenience foods; however this may be untrue as Short has shown that preparation of home meals includes both raw and prepared food products. ${ }^{15}$

\section{ACQUISITION OF COOKING SKILLS AND INFLUENCING FACTORS}

Consumers can develop cooking knowledge and skills from many possible sources ranging from family members to television shows. The numerous factors which influence the degree of one's cooking knowledge and skills and how they are acquired are age, gender, social/education class, social environment and attitude. These learning sources and influencing factors will be discussed in this section.

\section{Learning Sources}

The main and first source of cooking knowledge and skills is through mothers. ${ }^{5}$ Regardless of social and economic class, mothers have been considered as the most important source for cooking competence with $76 \%$ of women and $58 \%$ of men respondents claiming they learned how to cook from their mothers. ${ }^{5}$ The second most important source for cooking knowledge and skills is through cooking classes with $48.6 \%$ of female and $15.0 \%$ of male respondents using this as a source. Other sources that have been reported by the respondents included other family members such as fathers and grandmothers, spouses or partners, friends, magazines, cooking programmes on television, and doctors.

\section{Gender}

Gender is the first influencing factor to be discussed. The gender construct created by society has led to the division of roles played by men and women within a family where women are given the responsibility of food provision which entails planning, purchasing, storing, preparation and disposal. $^{5,9,16}$ This designated role may be the reason as to why we see a large dependence on mothers by children for learning how to cook. It is also believed by men that if their spouse has cooking competence, he will be taken care of and not need to develop or improve his cooking competence. ${ }^{5}$ This has led to women not only developing higher cooking skills, but also developing them at an earlier age. As compared to women who learn cooking from an early age using school and books, men are more likely to first learn from their wives or partners. ${ }^{5}$ Additionally, only $29.4 \%$ of the male respondents used cooking books as learning sources as opposed to $55.7 \%$ of the female respondents. With higher levels of cooking competence, it can be assumed that women cook more often. Caraher et al. support this, as they found 
that four out of five women cooked daily as compared to only one out of five men. Females $(94.3 \%)$ were also more confident of their cooking competence and being able to cook from scratch than men $(80.3 \%) .{ }^{5}$ Furthermore, men seem to lack the planning and organizing skills necessary for food shopping. Only 7\% of male respondents were responsible for food shopping because they were more skilled and knowledgeable than their partners. ${ }^{9}$ When females were asked as to why they took the responsibility of food shopping, many claimed that their spouse did not plan ahead for meals, wasted time and spent more money, with the end result of still not having the necessary foods to create a meal. Women also took the role of food provider because they knew their family's food preferences better than their spouse did. ${ }^{9}$ These findings are also reported by Larson et al. who concluded that females carry out food preparation nearly twice as often than men and that males tend to buy less fresh produce, not write grocery lists and use more convenience food products. ${ }^{10}$ Overall, there is strong empirical evidence that women possess more cooking competence required for several stages of the home food production chain.

\section{Age}

The second factor that influences cooking skills is age. At younger ages, the acquisition of cooking knowledge and skills is mainly through mothers, other family members and cooking classes; but as people get older, their learning source shifts to cooking books. However, this lean towards cooking books is dependent on the consumer's social and educational class. $^{5}$ Also, as stated previously with gender, men have become reliant on women to prepare home meals; however, it should be noted that there is an increasing demographic trend of younger single males. In comparison to older men, younger single men have reported attending more cooking classes as they can no longer rely on a spouse to provide food for them. ${ }^{5}$ Furthermore, as one gets older, his or her techniques and confidence of cooking competence increases and improves. With more practice and routine, confidence of techniques such as stewing, braising and casseroling positively correlates with age. ${ }^{5}$ In a study of older Swedish women by Sidenvall et al., it was shown that cooking competence improves because of routine experiences. ${ }^{16}$ The respondents knew by practice which items to start cooking first when preparing a meal so that all the items were ready at the same time. Through experience, they were aware of items, such as meat or potatoes, which will take longer to cook and so began with their preparation first. ${ }^{16}$ Experience also allows the meal preparer to learn through trial and error of what foods their spouses and children do not enjoy or are allergic to, and as such, older women find it easier to cater for their family's particular food tastes. ${ }^{6}$ Another cooking skill improved through practice is being able to memorize the items needed for several dishes. Instead of using a recipe, older women are able to prepare meals from memory and rely less on measuring devices as they use as much as they find necessary. The older Swedish women also displayed the skill of multi-tasking. ${ }^{16}$ They were able to cook several portions of a meal simultaneously because they were familiar with the techniques and cooking times. The older women were also able to prepare two dishes from one product, thus saving money and time from buying groceries again. Despite improved cooking competence amongst older women, their physical conditions, such as deteriorated eye vision or muscle weakness, may interfere with their abilities and thus some have had to reduce their cooking efforts to create simplified meals. ${ }^{16}$ Furthermore, the general trend of confidence in cooking techniques is that it increases with age, however it was seen this trend did not apply to microwaving. ${ }^{5}$ This may show that cooking competence is evolving as new food preparation methods are being invented. Those who are younger should be more familiar with microwaving than an elderly person.

\section{Income and Social/Educational Class}

Income and social/educational class contribute to determining cooking competence as they influence how people acquire them. Those in higher educational and social classes use cooking books as an important learning source whereas lower educational and social classes are more reliant on cooking classes at school which are free. ${ }^{5}$ Additionally, income and social class were found to have an influence on consumption of pre-prepared convenience foods. $28.5 \%$ of consumers with higher income, more than double as seen with lower income consumers, bought prepared meals within the last week prior to filling out the survey. Meanwhile, only one fifth of lower social classes, as opposed to one quarter of higher social classes, consumed a pre-prepared meal within the same timeframe. ${ }^{5}$ This study shows an indirect link with income/social class and the level of cooking knowledge and skills. It is unclear if these results of the study correlate to lower cooking competence or if they are simply the result of having enough money to purchase the more expensive preprepared foods. Additionally, it is difficult to correlate the participants' purchasing of pre-prepared foods with cooking competence as they could be purchasing the healthier choice of pre-prepared foods. Further research should be made to establish the nature of the link between income/social class and cooking competence.

\section{Social Environment}

The social environment of a consumer also plays a role in determining the acquisition and level of cooking competence. The influence of the social gender construct has already been discussed, but there are other influential factors such as women's satisfaction from caring for the family, changes in household structure, peer pressure and parents.

\section{Satisfaction}

The meal provider naturally wants to please those they are feeding $^{6}$ and through accomplishing this, they feel a sense of 
satisfaction and pride. ${ }^{6}$ When a woman's cooking is not enjoyed by her husband, it drives her to improve her cooking competence, as documented in this statement, 'it was really a lot of strain, to make two men happy, who were judging you. So that kind of pushed me a little to learn fast ${ }^{6} .{ }^{6}$ Once the family enjoys the meal, the meal provider feels a sense of success and pride as one participant proudly told the researcher that her husband "likes the way she cooks and that he has gained so much weight that people tease about what a good cook she must be'. 6 This sense of pride was also seen in another participant who said, 'I like to cook things that make my family happy... I live to cook things that make my husband lean back in his seat and say "that was a good dinner." That's very important'.

\section{Household Structure Dynamics}

Changes in household structure are also an important factor. Sidenvall et al. found from a literature review of previous studies that when a child moves away from the family or a spouse dies, the female food provider may change their food habits and frequency of meal preparation. The loneliness and bereavement resulting from the change in household dynamics can lead to a lack of motivation to prepare meals regularly and negatively affects food choices. This could be because as stated earlier, their satisfaction of providing and caring for their family disappears. Devault showed that a newly divorced mother found she was no longer bound to her duty to prepare complex meals which had been routinely prepared for her husband and children and now prepared simpler meals. ${ }^{6}$ However, if the woman still lives with her spouse, she will continue to take responsibility for food preparation. In contrast to older women, that literature review also showed that older men who are retired and living alone can improve their food choices, become more involved with meal preparation and enjoy cooking. ${ }^{16}$

\section{Adolescents and Parental Influence}

In regards to adolescents, their social environment impacts their behaviours significantly through peer pressure. As such, it is not 'cool' to eat healthily, ${ }^{14}$ and thus, may also negatively affect learning to cook at a young age. Parents influence their child's food behaviour by the family environment that they create. Out of numerous factors, of which time, convenience and taste were of primary importance, parental influence on adolescents' food behaviour was placed in the second level of importance. ${ }^{14}$ Parents can influence their child by setting an example through their own food purchasing, eating and cooking behaviours, to name a few. Adolescents in the study by Neumark-Sztainer et al. stated that they eat convenience food items often during the week when their parents are time constrained. This is of importance as the cooking knowledge and skills learnt by children from their parents is reduced and instead replaced by convenience food products. ${ }^{15}$

\section{Attitude}

Lastly, attitude towards cooking also determines a consumer's cooking competence as it can be seen as a barrier to acquiring or improving cooking skills. ${ }^{17}$ The majority of the respondents believed that cooking knowledge and skills should be taught to children, both boys and girls; however we see that there is a bias in the actual level of competence between genders. ${ }^{5}$ As stated earlier, many men assume that they do not require cooking competence because they believe women will provide food for them. ${ }^{5,} 9$ However, we are seeing a shift in traditional attitudes as young single men are becoming more reliant on their own cooking competence, ${ }^{5}$ while some women are uninterested in continuing this gender role and do not want to learn or improve their cooking skills, ${ }^{17}$ as seen by a woman who refused to learn as a resistance to gendered housework. ${ }^{6:}{ }^{104}$ As concluded in the literature reviews by Buckley et al. and Candel, this negative attitude towards cooking results in a convenience orientation attitude with the consumer being more inclined to purchase convenience food products; whereas enjoyment of cooking has the opposite effect and decreases convenience orientation. ${ }^{3,4,18}$ Buckley et al. categorized consumers into four different lifestyle groups: food connoisseurs, home meal preparers, kitchen evaders and convenience seeking grazers. The food connoisseurs had the greatest enjoyment from cooking and meal preparation and consumed the least amount of convenience foods as they did not view convenience foods as the typical 'time saving' food product. Devault found that some enjoyed cooking as a means to have alone time while their spouse took care of the children. ${ }^{6}$

\section{Measuring CoOking Competence}

In order to measure cooking competence, one must first define the term 'cooking skills.' Cooking skills have been typically defined as a set of mechanical or physical skills used in meal preparation. ${ }^{15}$ However, Caraher et al. stated that 'cooking skills in themselves do not guarantee the preparation of meals from basic ingredients. Many people lack the ideas, knowledge and menu-planning skills necessary to organize a meal. ${ }^{5}$ Similarly, Short found that the current definition of cooking skills may be much more complex and abstract than previously believed. ${ }^{15}$ During that study, it was observed that cooking skills were more than just mechanical tasks, but also involved conceptual, perceptual, planning, and fundamental skills of food nutrition, hygiene and chemistry. Perceptual skills consist of knowing what happens when certain food items are combined or heated and this skill can be seen with the study of older Swedish women who knew how long it would take for certain food items to cook when heated. ${ }^{16}$ Planning skills are essential and require constant monitoring and adaptation of daily meals such that they are not repetitive and still satisfy everyone's tastes. ${ }^{6: 48}$ Being able to plan out the family's meals for the entire week can be very stressful as found by one participant who said, 
'my biggest peeve about cooking, preparing three meals a day, is trying to figure out what to put on the table. If somebody would just send me menus every week, and I could provide the mechanics, that would take a lot of the hassle away'. ${ }^{6}$ As seen with one meal preparer who stated about her husband and children, '...he doesn't like pork chops...he doesn't like potatoes too well, so I'll usually have stuffing... my children aren't much on eating beans...they'll eat meat, but they won't eat a lot of beef...they love spinach..., 6:40 the meal preparer also has to overcome the obstacle of everyone's individual food tastes to create a dish which will be enjoyed by all. Other skills noted were multitasking such as taking care of children while cooking ${ }^{15}$ and reproducing a meal without recipes as seen with the women in the Sindervall et al. study. ${ }^{16}$

Instead of looking at skills from a 'task-centered' approach, a 'person-centered' approach may be helpful to understand cooking skills. This approach divides cooking skills into two different categories: domestic cooking skills and professional cooking skills. ${ }^{15}$ These can be seen as two sets of skills that have similar and different aspects. Both share the technical skills of chopping, boiling, etc. but the situations in which they prepare food as well as their kitchen equipment are different. A professional chef would have the knowledge and skills of preparing consistent food quality and preparing several dishes simultaneously; while a domestic cook would have the knowledge and skills of creating dishes from leftovers, multi-tasking with children or house chores, and preparing food to meet dietary requirements and tastes of the family. ${ }^{15}$

There is a gap in research about measuring cooking competence and those questionnaires which have been created to measure cooking knowledge and skills have generally examined technical skills only, as in the study by McLaughlin et al. ${ }^{13}$ Methods used to measure food preparation entailed examining recipes and the skills used to prepare the meal. Only technical skills were measured: washing, subdivision and fractionation, combining and mixing, and applied. The amount of ingredients was also used to measure complexity of meals. ${ }^{13}$ Opposite to that, Anderson et al. used methods which did not solely examine technical skills when assessing the validity and reliability of a nutrition knowledge questionnaire. ${ }^{1}$ The methods used to measure food preparation and cooking competence involved examining knowledge of ingredients to create a certain meal and how long specific food items took to cook; however, this questionnaire was very limited. ${ }^{1}$ Larson et al. measured food preparation and purchasing behaviour as part of buying fresh vegetables, such as writing a grocery list, preparing a green salad, preparing a dinner with chicken, fish or vegetables, and preparing a meal for at least two people. ${ }^{10}$ These measurements entail basic food knowledge of knowing when a fresh produce is ripe and not damaged, planning skills, technical skills and creating a meal that will be enjoyed by multiple people.

\section{Conclusions AND OUTLOOK ON Future RESEARCH}

The convenience food industry has been increasing steadily as more and more ways are being developed to serve customers who are time-constrained. ${ }^{7}$ This is of concern as many believe that this is leading to the deskilling of cooking as we will no longer have to rely on our own cooking competence to produce meals. ${ }^{15}$ In order to understand the influence of cooking competence on the purchasing of convenience foods, one must first have a thorough understanding of what cooking competence entails. Possession of cooking knowledge and skills allows the consumer to be self reliant, ${ }^{5}$ to have a healthy $\operatorname{diet}^{11}$ and makes the home food production process less stressful. As research has shown, the addition of cooking competence to nutrition knowledge assists in the attainment of healthy dietary standards as they allow the consumer to be able to use healthy preparation techniques to prepare a vast array of foods. ${ }^{5,12}$ Cooking competence also impacts what consumers purchase. If a consumer lacks preparation knowledge and skills than he or she will lean towards purchasing preprepared convenience foods instead of raw fresh foods. ${ }^{11,17}$

Mothers and cooking classes are the most important sources to acquire cooking skills, ${ }^{5}$ and this is of concern as cooking classes such as in Britain, have been and are being removed and replaced with classes which cover nutrition knowledge only. ${ }^{8}$ Factors which determine how one acquires their cooking knowledge and skills or their level of competence include gender, age, income and social/educational class, attitude, ${ }^{5,} 16$ and social environment. ${ }^{14,}{ }^{16}$ There is a lack of information regarding social environmental factors and their impact on cooking competence as much research has been focused on their impact on food consumption instead. Larson et al. briefly examined the influence of ethnicity and the consumer's living situation, e.g. campus housing vs. apartment, however there needs to be further investigation. Further research also needs to investigate the effects of having a positive environment which would encourage the development of cooking knowledge and skills rather than a negative environment. This could entail family or friends who enjoy cooking and getting together for potlucks versus family or friends who would prefer to order take-out or purchase preprepared meals. An example of positive environment is seen by one of the participants in the study by Devault who commented 'one of my friends likes to cook and is interested in cooking, and she had children at the same time I did... so we both would compare notes about what was a good thing to do and... how important early nutrition is for your life'. Additionally, if a domestic cooking skill definition is used, research should look into how the social environment affects the individual stages of the home food production chain. For example, peer pressure may influence an adolescent not wanting to assist with planning and purchasing as it may not 
be 'cool' to be shopping with your parents in a grocery store. In general, a deeper examination of the influence from parents, peer pressure, household structure, living situation, ethnicity, and women's satisfaction from cooking for others needs to be taken in order to understand how one's environment can affect a person's acquisition and expansion of cooking knowledge and skills.

Cooking knowledge and skills is much more complex and abstract than the traditional 'task-centered' approach generally taken. ${ }^{15}$ By taking a different approach, the concept of a domestic cooking skills category may be more useful in examining and understanding these skills as they are more comprehensive of the set of skills used during domestic cooking in a regular household. ${ }^{15}$ This could mean that domestic cooking skills will affect several stages of the home food production process. Being able to conceptualize certain meals ahead of time, planning a grocery list and placing the items into food categories, such that shopping will be organized, would entail the planning and purchasing stages. Fundamental knowledge of knowing not to leave dairy products out of the fridge for too long and to clean up thoroughly after cooking with raw chicken would affect the storing/handling and disposal/tidy-up stages, respectively. Technical skills and multi-tasking would affect the preparation stage, and lastly, the skill of being able to take care of children throughout all the stages, whether it be purchasing or preparation, would be very beneficial.

\section{Cooking Competence Questionnaire}

With a non-traditional cooking skills definition, a more comprehensive questionnaire of measuring cooking competence needs to be developed. As mentioned previously, there has been a gap in research about measuring cooking competence and the associated survey tools which do not cover the broad array of various tasks entailed in domestic cooking. An inventory of measurements has been collected:

- Measuring the preparation of a single meal by giving one point for each time a food preparation technique was used. Techniques included washing, subdivision and fractionation, combining and mixing, heating, and the removal of heat. ${ }^{13}$

- The use of recipes, number of foods in the recipe, number of foods reported but not part of a recipe, and time of cooking, were used to categorize food preparation activity into three strata (high, medium and low)..$^{13}$

- Measured knowledge of ingredients for preparing basic meals and assigned one point for each correct ingredient. The meals used for the study were coleslaw, lentil soup, bread and apple crumble. ${ }^{1}$

- Measured knowledge of cooking time of common foods such as vegetable stir-fry, broccoli, pasta shells, white rice (not easy cook) and boiled potatoes. One point assigned for correct times. ${ }^{1}$

- Measured behaviours of participants over the previous 12 months such as buying fresh vegetables, writing a grocery list, preparing a green salad, preparing a dinner with chicken, fish, or vegetables, and preparing an entire dinner for two or more people. These behaviours were measured by frequency according to 'never,' 'one to two times,' 'four to five times,' 'monthly,' 'weekly,' or 'daily.' 10

These measurements do not encompass the broad variety of tasks associated with domestic cooking competence. McLaughlin et al. focuses on the technical skills, ${ }^{13}$ while Anderson et al. (2001) and Larson et al. (2006) have measured other skills but their surveys are still not comprehensive of domestic cooking., 10

Technical, planning, perceptual, conceptual, basic food knowledge and other cooking-related skills all need to be included into a questionnaire. Possible items for measurement that have not yet been used could include memorization of recipes, using ingredients without measuring devices, simultaneously doing other house chores while cooking, clean-up after use of raw chicken, utilizing leftovers and making two dishes out of one food product. A list of items that represent a comprehensive definition of domestic cooking competence can be created and completed by participants using a scale of 1- never, 2- rarely, 3sometimes, 4- often, and 5- all the time. An example of a list is:

1. I make meals that require more than three ingredients (typically packaged convenience foods like Kraft Dinner Easy-Mac need only a couple more ingredients to complete the meal). ${ }^{13}$

2. I am able to visualize the meal I am going to make and how the food items will come together on the plate.

3. I make a grocery list; ${ }^{10}$ I plan food for the week; I plan what meals I will make each day.

4. I am aware of the necessary food hygiene measures to take while preparing food and cleaning up.

5. I do not need to use recipes because I know through experience which combinations of ingredients can make a tasty meal.

6. I am able to create a meal out of leftovers.

7. I am able to do house chores while cooking.

8. I am distracted from cooking and meal preparation whenever my children are around.

9. I create meals from scratch without convenience food ingredients.

10. I know my family's specific food tastes/requirements.

11. I know how to create home-made meals that both satisfy my family and do not involve convenience foods.

12. I do not need to use measuring devices (ex: cups, tbsp, tsp, scale) when I create meals from scratch.

13. I know how long certain food items (potatoes, meat, lasagne) will take to cook. 
14. I can plan according to food item cooking times so that all the items are completed and served at the same time.

15. I make sure I have the basic ingredients on storage.

16. I am flexible and can make a meal out of whatever ingredients I have within the house.

An additional measure which can also be compared and correlated to cooking skills and individual items on the list is 'Which mechanical skills are you capable of successfully carrying out: boiling, baking, stewing, chopping, blending, steaming, poaching, frying, grilling, peeling, braising.' This comprehensive set of measurements for domestic cooking competence would cover all of the categories of technical, conceptual, perceptual, planning, basic food knowledge and other non-categorical cookingrelated skills. Without a new approach to their definition, the understanding of cooking competence and their impacts on eating behaviour and food purchasing may not be fully realized.

\section{ENDNOTES}

${ }^{\text {a }}$ Healthy People 2010 is a set of objectives for the people of the U.S.A. to have longer and healthier lives which can be attained by improving dietary behaviour (http://www.healthypeople.gov/default.htm).

\section{REFERENCES}

1. Anderson, A.S., Bell, A., Adamson, A. and Moynihan, P. (2001). A questionnaire assessment of nutrition knowledge - validity and reliability issues. Public Health Nutrition 5(3): 497-503.

2. Botonaki, A., Natos, D. and Mattas, K. (2009). Exploring convenience food consumption through a structural equation model. Journal of Food Products Marketing 15(1): 64-79.

3. Buckley, M., Cowan, C. and McCarthy, M. (2007). The convenience food market in Great Britain: Convenience food lifestyle segments. Appetite 49(3): 600-617.

4. Candel, M.J.J.M. (2001). Consumers' convenience orientation towards meal preparation: conceptualization and measurement. Appetite 36(1): 15-28.

5. Caraher, M., Dixon, P., Lang, T. and Carr-Hill, R. (1999). The state of cooking in England: the relationship of cooking skills to food choice. British Food Journal 101(8): 590-609.
6. Devault, M.L. (1991). Feeding the family: The social organization of caring as gendered work. The University of Chicago Press: Chicago and London.

7. Friddle, C.G., Mangaraj, S. and Kinsey, J.D. (2001). The food service industry: Trends and changing structure in the new millennium. Department of Economics. University of Minnesota.

8. Frobisher, C., Jepson, M. and Maxwell, S.M. (2005). The attitudes and nutritional knowledge of 11-to12year-olds in Merseyside and Northern Ireland. International Journal of Consumer Studies 29(3): 200207.

9. Lake, A.A., Hyland, R.M., Mathers, J.C., Rugg-Gunn, A.J., Wood, C.E. and Adamson, A.J. (2006). Food shopping and preparation among the 30-somethings: whose job is it? (The ASH30 study). British Food Journal 108(6): 475-486.

10. Larson, N.I., Perry, C.L., Story, M. and NeumarkSztainer, D. (2006). Food preparation by young adults is associated with better diet quality. J Am Diet Assoc. 106: 2001-2007.

11. Levy, J. and Auld, G. (2004). Cooking classes outperform cooking demonstrations for college sophomores. J. Nutr. Educ. Behav. 36(4): 197-203.

12. Liquori, T., Koch, P.D., Contento, I.R. and Castle, J. (1998). The cookshop program: outcome evaluation of a nutrition education program linking lunchroom food experiences with classroom cooking experiences.

Journal of Nutrition Education 30(5): 302-313.

13. McLaughlin, C., Tarasuk, V. and Kreiger, N. (2003). An examination of at-home food preparation activity among low-income, food-insecure women. J. Am. Diet Assoc. 103(11): 1506-1512.

14. Neumark-Sztainer, D., Story, M., Perry, C. And Casey, M.A. (1999). Factors influencing food choices of adolescents: Findings from focus-group discussions with adolescents. J Am Diet Assoc. 99: 929-937.

15. Short, Frances. (2003). Domestic cooking skills - what are they? Journal of the HEIA 10(3): 13-22.

16. Sidenvall, B., Nydahl, M. and Fjellström, C. (2001). Managing food shopping and cooking: the experiences of older Swedish women. Ageing and Society 21: 151168.

17. Soliah \& Walter. (2006). Quantifying the impact of food preparation skills among college women. College Student Journal 40(4): 729-739.

18. Wales, M. (2009). Understanding the role of convenience in consumer food choices: a review article. SURG 2(2): 40-48. 